\title{
ANALISIS PENERAPAN STANDAR AKUNTANSI KEUANGAN ENTITAS TANPA AKUNTABILITAS PUBLIK (SAK ETAP) TERHADAP LAPORAN KEUANGAN PADA USAHA KECIL MENENGAH BAHAGA MANADO
}

\author{
Ni Gusti Ayu Kade Suwintari ${ }^{1}$, Lintje Kalangi ${ }^{2}$, Anneke Wangkar $^{3}$ \\ 1,2,3 Jurusan Akuntansi, Fakultas Ekonomi dan Bisnis Universitas Sam Ratulangi, Jl. Kampus Bahu, Manado, \\ 95115, Indonesia \\ E-mail : ayu_suwintari@yahoo.com
}

\begin{abstract}
Small and medium enterprises (SMEs) are productive economic enterprises owned by individuals or business entities. Business activities undertaken by small and medium enterprises require a financial statement that reflects the business activities undertaken during one period. The financial statements are a form of corporate management accountability by management to external and internal parties. Seeing the importance of usability, the financial statements should be structured according to the applicable standards in order to be interpreted with the same concept and understanding by its users. The generally accepted Financial Accounting Standards make it difficult for small and medium enterprises (SMEs) who only have minimal accounting knowledge in preparing financial statements. The Financial Accounting Standards Entity Without Public Accountability (SAK ETAP) comes with the aim to accommodate the needs of entities that have no significant public accountability in the conduct of their business such as SMEs. The purpose of this study is to determine the application of Financial Accounting Standards Entity Without Public Accountability (SAK ETAP) Against Manado Financial Report. This research uses descriptive-comparative research type. The results show that Manado Manado has not fully implemented the Financial Accounting Standards of Non-Accountable Public Entity (SAK ETAP) in its financial statements. This is because the financial manpower of Manado Manado does not have sufficient knowledge about the Financial Accounting Standards of Non-Public Accountable Entity (SAK ETAP) so that it becomes a factor that Manado Bahaga has not fully implemented SAK ETAP. Instead, the company employs a competent financial personnel in their field so that they can produce financial statements in accordance with SAK ETAP.
\end{abstract}

Keywords: SAK ETAP, Financial Statements, SMEs

\section{PENDAHULUAN}

Dalam perekonomian di Indonesia, usaha-usaha atau badan usaha dan bisnis sangat berperan penting untuk pertumbuhan ekonomi. Dilihat dari sisi perkembangannya usaha kecil menengah menjadi suatu sarana aktivitas ekonomi bagi masyarakat dalam menyediakan sumber penghasilan, tenaga kerja dan juga merupakan suatu bentuk pola pemikiran yang kreatif di jaman globalisasi ini. Dalam perkembangannya di Indonesia Usaha Kecil Menengah (UKM) sudah sangat berkembang, dan sangat banyak jenis usahanya. Maka hal itu dapat memberikan kontribusi yang sangat dalam bagi perekonomian Indonesia. Usaha Kecil Menengah merupakan suatu kegiatan masyarakat dalam bentuk badan usaha yang menggunakan keterampilan dan inisiatif yang tinggi. Dimana orang yang menjalankan usaha ini harus memiliki sikap dan mental yang besar. Usaha Kecil Menengah ini memiliki berbagai jenis usaha, namun tetap memiliki pencatatan akuntansi didalamnya. 
Pada umumnya, Usaha Kecil Menengah (UKM) masih menerapkan akuntansi yang sederhana dengan tidak melihat standar akuntansi yang baik dan benar. Masalah akan timbul jika penerapan akuntansi tidak dilakukan dengan baik dan benar, sehingga membuat pemilik UKM menetapkan keputusan dengan cara memperkirakan tanpa memiliki dasar yang kuat untuk mengambil keputusan tersebut. Adapun masalah yang sering dihadapi oleh UKM yaitu pencatatan dan penyusunan laporan keuangan yang masih sangat sederhana dan terlihat belum memadai karena UKM mengalami banyak hambatan dalam pembuatannya. Salah satu faktor yaitu kurangnya keterampilan yang dimiliki dalam melakukan pencatatan akuntansi, karena UKM kebanyakan hanya mencatat jumlah barang diterima dan dikeluarkan, jumlah barang dibeli dan dijual, serta jumlah piutang dan hutang, tanpa menggunakan standar akuntansi keuangan yang ada, sehingga belum mencerminkan informasi keuangan yang sebenarnya. Menyadari situasi dan kondisi ini, maka sangat diperlukan inovasi penyusunan laporan keuangan sesuai dengan standar akuntansi keuangan. maupun kreditor dalam memberikan bantuan pembiayaan bagi para pengusaha UKM.

\section{TINJAUAN PUSTAKA}

\subsection{Akuntansi}

Menurut Warren, Reeve, dan Duchac (2017:7) Akuntansi merupakan sistem informasi yang menyediakan laporan kepada para pemakai laporan keuangan mengenai aktivitas perusahaan.

\subsection{Akuntansi Keuangan}

Bidang akuntansi keuangan berhubungan secara keseluruhan dengan akuntansi suatu entitas. Akuntansi keuangan adalah cabang akuntansi yang informasinya lebih dititikberatkan untuk memenuhi kebutuhan pihak ekstern perusahaan. Laporan keuangan yang disajikan bertujuan untuk memenuhi kebutuhan pemimpin perusahaan, pemilik, pemerintah, dan masyarakat dalam pengambilan keputusan.

\subsection{Standar Akuntansi Keuangan (SAK)}

SAK adalah pernyataan dan interpretasi yang disusun oleh Dewan Standar Akuntansi Keuangan Ikatan Akuntansi Indonesia (DSAK IAI), terdiri dari Pernyataan Standar Akuntansi Keuangan (PSAK) dan Interpretasi Standar Akuntansi Keuangan (ISAK) (Surya, 2012:6). Standar akuntansi keuangan juga merupakan kerangka prosedur yang digunakan sebagai acuan dalam pembuatan laporan keuangan sehingga perusahaan memperoleh keseragaman dalam menyajikan laporan keuangan.

\subsection{Standar Akuntansi Keuangan Entitas Tanpa Akuntabilitas Publik}

Menurut SAK ETAP (2009) Standar Akuntansi Keuangan untuk Entitas Tanpa Akuntanbilitas Publik (SAK ETAP) dimaksudkan untuk digunakan Entitas Tanpa Akuntabilitas Publik. Entitas tanpa akuntabilitas publik adalah entitas yang tidak memiliki akuntabilitas publik signifikan dan mereka mengeluarkan laporan keuangan untuk tujuan umum bagi para pengguna eksternal.

\subsection{Pelaporan Keuangan Entitas Tanpa Akuntabilitas Publik}

Menurut Ikatan Akuntan Indonesia dalam SAK ETAP (2009), laporan keuangan adalah bagian dari proses pelaporan keuangan, dan laporan keuangan yang lengkap meliputi : neraca, laporan laba rugi, laporan perubahan modal, laporan arus kas, dan catatan atas laporan keuangan.

\subsection{Penyajian Laporan Keuangan}

Penyajian secara wajar di dalam laporan keuangan sesuai dengan SAK ETAP, yaitu Laporan keuangan menyajikan secara wajar laporan posisi keuangan, kinerja keuangan, dan arus kas suatu entitas. Penyajian laporan keuangan yang wajar juga mensyaratkan penyajian yang jujur atas pengaruh transaksi, peristiwa dan kondisi lain sesuai pengertian dan kriteria pengakuan aset, kewajiban, pendapatan, dan beban. 


\subsection{Usaha Kecil Menengah (UKM)}

\subsubsection{Pengertian Usaha Kecil Menengah}

Usaha Kecil Menengah atau yang sering disingkat UKM ialah salah satu bagian penting dari perekonomian suatu negara maupun daerah, begitu juga dengan negara Indonesia. Usaha Kecil Menengah merupakan kegiatan ekonomi rakyat yang berskala kecil dan menengah berupa bidang usaha yang secara keseluruhan merupakan kegiatan usaha kecil dan menengah serta perlu dilindungi untuk mencegah dari persaingan usaha yang tidak sehat.

\subsubsection{Karakteristik Usaha Kecil}

Pada dasarnya, sektor usaha-usaha kecil memiliki karakteristik-karakteristik sebagai berikut, di antaranya:

a) Sistem pembukuan yang relatif sederhana dan cenderung tidak mengikuti kaidah administrasi pembukuan standar.

b) Modal terbatas.

c) Kemampuan pemasaran dan negosiasi serta diversifikasi pasar sangat terbatas.

\subsubsection{Kriteria Usaha Kecil Menengah}

Kriteria Usaha Kecil Menengah menurut Undang- Undang Nomor 20 Tahun 2008 Pasal 6 adalah sebagai berikut:

1. Usaha Kecil

a) Mempunyai kekayaan bersih paling banyak Rp500.000.000,00 (Lima Ratus Juta Rupiah) dan tidak termasuk tanah serta bangunan tempat usaha; atau

b) Mempunyai hasil dari penjualan tahunan paling banyak Rp2.500.000.000,00 (Dua Miliar Lima Ratus Juta Rupiah).

2. Usaha Menengah

a) Memiliki angka kekayaan bersih lebih dari Rp500.000.000,00 (Lima Ratus Juta Rupiah), yang paling banyak Rp10.000.000.000,00 (Sepuluh Miliar Rupiah) dan tidak termasuk tanah serta bangunan yang menjadi tempat usaha; atau

b) Mempunyai hasil dari penjualan tahunan lebih dari Rp2.500.000.000,00 (Dua Milyar Lima Ratus Juta Rupiah) sampai dengan yang paling banyak Rp50.000.000.000,00 (Lima Puluh Miliar Rupiah).

\subsection{Metode Pencatatan Akuntansi}

Ardiyos (2008:166) menjelaskan pengertian cash basis accounting method (metode akuntansi dasar kas) adalah suatu metode akuntansi dimana biaya/pendapatan dicatat saat dibayar/diterima tanpa menghubungkan dengan periode untuk kapan biaya/pendapatan terjadi. Adriyos (2008:19) mendefinisikan accrual basis accounting method sebagai suatu metode akuntansi yang mencatat atau mengakui beban maupun pendapatan saat terjadinya, yaitu beban dicatatnya pada saat barang atau jasa diterima sedang pendapatan dicatat pada saat barang-barang atau jasa diserahkan tanpa menghiraukan saaat pengeluaran maupun penerimaan dari yang bersangkutan.

\subsection{Tujuan Laporan Keuangan}

Ikatan Akuntan Indonesia menjelaskan tujuan laporan keuangan yaitu menyediakan informasi posisi keuangan, kinerja keuangan, dan laporan arus kas suatu entitas yang bermanfaat untuk sejumlah besar penggunanya dalam pengambilan keputusan ekonomi.

\subsection{Pengguna Laporan Keuangan}

Purba (2009:33) menjelaskan pada dasarnya, pemakai laporan keuangan terbagi atas dua kelompok, yaitu pemakai eksternal dan internal. Yang termasuk kelompok pemakai laporan keuangan internal adalah manajemen. Manajemen berkepentingan melihat besar kecilnya laba perusahaan untuk melakukan evaluasi kinerja keuangan. Informasi pada laporan keuangan juga dibutuhkan untuk menentukan strategi, pengawasan dan menjadi ukuran dalam memberikan insentif karyawan. Manajemen bertanggung jawab atas penyajian dan penyusunan laporan keuangan. Kelompok pemakai laporan keuangan eksternal diuraikan 
oleh Purba (2009:34-35), yaitu sebagai berikut: investor, pemberi pinjaman, masyarakat, pemerintah dan badan regulator lainnya, pemasok dan kreditur usaha lainnya, pelanggan, dan karyawan.

\section{METODE PENELITIAN}

\subsection{Jenis Penelitian}

Jenis Penelitian yang digunakan dalam penelitian ini adalah penelitian deskriptifkomparatif. Deskriptif merupakan suatu pengelolaan data dengan mempelajari hasil yang diperoleh pada saat pencarian data, kemudian dilakukan reduksi data dengan membuat rangkuman dan diperoleh kesimpulan hasil penelitian. Sedangkan Komparatif adalah jenis penelitian yang dilakukan dengan cara membandingkan laporan keuangan Bahaga Manado dengan laporan keuangan yang sesuai dengan SAK ETAP.

\subsection{Waktu dan Tempat Penelitian}

Penelitian ini dilakukan pada:

Nama Objek : : Bahaga Manado

Alamat : Jl. B.W. Lapian No.32A Tikala Kumaraka, Wenang.

Waktu Penelitian : April 2018.

\subsection{Metode Analisis}

Dalam menganalisis data, penulis menggunakan metode sebagai berikut:

1. Deskriptif, dimana data dikumpulkan, disusun, diinterpretasikan dan dianalisis sehingga memberikan keterangan yang lengkap bagi masalah yang dihadapi.

2. Komparatif, dimana analisis dilakukan dengan membandingkan teori-teori dan standar yang berlaku sekarang ini, yaitu Standar Akuntansi Keuangan Entitas Tanpa Akuntabilitas Publik (SAK ETAP) khususnya laporan keuangan, dengan penerapannya pada perusahaan Bahaga Manado kemudian diambillah kesimpulan dari hasil perbandingan.

\section{HASIL ANALISIS DAN PEMBAHASAN}

\subsection{Hasil analisis}

Berdasarkan hasil wawancara yang dilakukan dengan bagian keuangan dan pemilik usaha kecil menengah perusahaaan Bahaga Manado sendiri maka di peroleh informasi yaitu, perusahaan Bahaga Manado merupakan perusahaan dagang yang memiliki produk berupa kaos dan souvenir yang siap untuk dijual secara tunai kepada konsumen. Perusahaan Bahaga Manado memiliki produk berupa kaos dengan berbagai jenis motif dan ukuran serta souvenir dengan beraneka macam bentuk seperti ikan, gantungan kunci, dan lain-lain. Dalam proses pemesanan barang, konsumen bisa langsung datang dan membeli barang yang sesuai dengan keinginan dan ada juga konsumen yang melakukan pemesanan produk berupa kaos dalam jumlah yang banyak.

Proses Pemesanan produk berupa kaos dalam jumlah banyak ini akan dimulai dengan mencatat dalam kartu pesanan, berapa jumlah barang yang di pesan, motif barang yang dipesan, dan ukuran barang yang dipesan kemudian karyawan perusahaan Bahaga Manado akan menyiapkan barang yang dipesan tersebut, setelah barang selesai disiapkan akan dilihat kembali jumlah, motif, dan ukuran barang yang dipesan apakah sudah sesuai dengan kartu pesanan jika sudah sesuai maka akan langsung di berikan kepada konsumen yang memesan barang tersebut. Barang yang baru saja diterima oleh konsumen tadi akan di catat oleh bagian pembukuan ke dalam buku kas masuk. Perusahaan Bahaga Manado membuat laporan keuangan yang bertujuan untuk menyediakan informasi keuangan pada periode tertentu bagi pihak-pihak yang berkepentingan dan juga sebagai bahan pertimbangan dalam mengambil suatu keputusan oleh perusahaan. Bahaga Manado membuat laporan keuangan secara perbulan dan laporan keuangan yang dibuat pada perusahaan Bahaga Manado merupakan laporan keuangan yang masih sangat sederhana dimana pencatatan yang dilakukan oleh 
Bahaga Manado hanya mencatat jumlah transaksi penjualan barang secara tunai ke dalam buku kas masuk dan semua transaksi-transaksi pengeluaran yang terjadi akan di catat ke dalam buku kas keluar serta jumlah modal yang di keluarkan akan di catat ke dalam buku rekapitulasi modal dan semua pencatatan ini akan di catat secara manual.

Dalam siklus akuntansi alur pencatatan di mulai dengan beberapa tahap pencatatan yaitu: transaksi, bukti transaksi, pencatatan ke dalam jurnal, pempostingan ke dalam buku besar, neraca saldo, jurnal penyesuaian, worksheet/kertas kerja, kemudian pembuatan laporan keuangan yang di dalamnya terdapat laporan laba/rugi, laporan perubahan modal, neraca dan arus kas, setelah membuat laporan keuangan kemudian selanjutnya membuat jurnal penutup. Dari siklus akuntansi tersebut dapat kita lihat bahwa perusahaan Bahaga Manado hanya melakukan pencatat akuntansi biasa saja dan perusahaan Bahaga Manado tidak membuat laporan keuangan. Berdasarkan Standar Akuntansi Keuangan Entitas Tanpa Akuntabilitas Publik laporan keuangan entitas yang sesuai dengan SAK ETAP merupakan laporan keuangan yang di dalamnya terdapat laporan yang berupa Neraca, Laporan Laba Rugi, Laporan Perubahan Ekuitas, Laporan Arus Kas, dan Catatan Atas Laporan Keuangan. Berikut laporan keuangan perusahaan Bahaga Manado yang dapat disajikan.

Tabel 4.1

Buku Kas Masuk Bahaga Bulan Maret 2018 Manado

\begin{tabular}{|c|c|c|c|}
\hline KETERANGAN & JUMLAH & HARGA SATUAN & TOTAL \\
\hline Kaos manado since & 12 & Rp. 100.000 & Rp. 1.200 .000 \\
\hline Souvenir rumah adat & 2 & Rp. 60.000 & $\begin{array}{ll}\text { Rp. } & 120.000\end{array}$ \\
\hline Souvenir ikan & 2 & Rp. 55.000 & $\begin{array}{ll}\text { Rp. } & 110.000 \\
\end{array}$ \\
\hline Gantungan kunci & 20 & $\begin{array}{ll}\text { Rp. } & 10.000 \\
\end{array}$ & $\begin{array}{ll}\text { Rp. } & 200.000 \\
\end{array}$ \\
\hline Kaos forgetable & 8 & Rp. 100.000 & $\begin{array}{ll}\text { Rp. } & 800.000\end{array}$ \\
\hline Kaos colecon & 6 & Rp. 100.000 & Rp. $\quad 600.000$ \\
\hline Kaos torang samua basudara & 10 & Rp. 100.000 & Rp. 1.000 .000 \\
\hline Kaos keep calm & 2 & Rp. 100.000 & $\begin{array}{ll}\text { Rp. } & 200.000 \\
\end{array}$ \\
\hline Kaos ciptaan Tuhan & 8 & Rp. 100.000 & Rp. $\quad 800.000$ \\
\hline Kaos dive bunaken & 5 & Rp. 100.000 & $\begin{array}{ll}\text { Rp. } & 500.000 \\
\end{array}$ \\
\hline Kaos I love manado & 1 & Rp. 100.000 & $\begin{array}{ll}\text { Rp. } & 100.000 \\
\end{array}$ \\
\hline Kaos cap tikus & 7 & Rp. 100.000 & $\begin{array}{ll}\text { Rp. } & 700.000 \\
\end{array}$ \\
\hline Kaos hobby mahal & 5 & Rp. 100.000 & $\begin{array}{ll}\text { Rp. } & 500.000 \\
\end{array}$ \\
\hline Manado contat & 3 & Rp. 50.000 & $\begin{array}{ll}\text { Rp. } & 150.000 \\
\end{array}$ \\
\hline Kaos bunaken yin yang & 2 & Rp. 100.000 & $\begin{array}{ll}\text { Rp. } & 200.000 \\
\end{array}$ \\
\hline Kaos un forgetable & 1 & Rp. 100.000 & $\begin{array}{ll}\text { Rp. } & 100.000 \\
\end{array}$ \\
\hline Kaos muka itu di rawat & 1 & Rp. 100.000 & $\begin{array}{ll}\text { Rp. } & 100.000 \\
\end{array}$ \\
\hline Kaos kota manado & 3 & Rp. 100.000 & Rp. $\quad 300.000$ \\
\hline Kaos God is Good & 6 & Rp. 100.000 & $\begin{array}{ll}\text { Rp. } & 600.000 \\
\end{array}$ \\
\hline Panjar konsumen & & & $\begin{array}{ll}\text { Rp. } & 360.000 \\
\end{array}$ \\
\hline Kaos badan bagini & 5 & Rp. 100.000 & $\begin{array}{ll}\text { Rp. } & 500.000 \\
\end{array}$ \\
\hline Kaos we have & 3 & Rp. 100.000 & $\begin{array}{ll}\text { Rp. } & 300.000 \\
\end{array}$ \\
\hline Kaos doa jang tabubale & 5 & Rp. 100.000 & $\begin{array}{ll}\text { Rp. } & 500.000 \\
\end{array}$ \\
\hline Kaos tong kosong & 6 & Rp. 100.000 & Rp. $\quad 600.000$ \\
\hline Kaos colecon orange & 7 & Rp. 100.000 & $\begin{array}{ll}\text { Rp. } & 700.000 \\
\end{array}$ \\
\hline Souvenir kalung & 1 & $\begin{array}{ll}\text { Rp. } & 10.000 \\
\end{array}$ & $\begin{array}{ll}\text { Rp. } & 10.000 \\
\end{array}$ \\
\hline Kaos kaya berkat & 2 & Rp. 100.000 & Rp. $\quad 200.000$ \\
\hline Souvenir kapal & 1 & Rp. 55.000 & $\begin{array}{ll}\text { Rp. } & 55.000 \\
\end{array}$ \\
\hline Kaos sito timo tou & 1 & Rp. 100.000 & $\begin{array}{ll}\text { Rp. } & 100.000 \\
\end{array}$ \\
\hline Souvenir burung manguni & 1 & Rp. 70.000 & $\begin{array}{ll}\text { Rp. } & 70.000 \\
\end{array}$ \\
\hline Kaos S.B & 12 & Rp. 100.000 & Rp. 1.200 .000 \\
\hline Kaos Yesus is my hero & 1 & Rp. 50.000 & $\begin{array}{ll}\text { Rp. } & 50.000 \\
\end{array}$ \\
\hline Kaos pilih mana & 2 & Rp. 100.000 & $\begin{array}{ll}\text { Rp. } & 200.000 \\
\end{array}$ \\
\hline Total & & & Rp. 13.125.000 \\
\hline
\end{tabular}


Dari Tabel 4.1 Buku Kas Masuk perusahaan Bahaga Manado dapat dilihat bahwa Bahaga Manado merupakan perusahaan dagang yang menjual produk berupa Kaos dan Souvenir dimana perkaos memiliki harga satuan Rp. 100.000 dan souvenir berupa : Rumah Adat dengan harga satuan Rp. 60.000, Souvenir Ikan Rp. 55.000, Gantunga Kunci Rp. 10.000 dan Burung Manguni Rp. 70.000 perusahaan Bahaga Manado mencatat semua pendapatan dari penjualan dengan cara merekap semua pendapatan perhari dari masing-masing motif kaos perusahaaan Bahaga Manado dan souvenir selama bulan Maret kemudian mencatatnya ke dalam Buku Kas Masuk yang dimiliki perusahaan Bahaga Manado. Perusahaan Bahaga Manado diharuskan melakukan stock opname, yaitu perhitungan persediaan barang yang masih ada di gudang untuk mengetahui berapa persediaan barang yang masih tersisa.

Tabel 4.2 Buku Kas Keluar Bahaga Bulan Maret 2018 Manado

\begin{tabular}{|c|c|c|c|}
\hline TANGGAL & KETERANGAN & \multicolumn{2}{|c|}{ JUMLAH } \\
\hline $8 / 3 / 2018$ & 1 Pak plastik & $\mathrm{Rp}$ & 16,500 \\
\hline \multirow[t]{2}{*}{ 9/3/2018 } & kertas 90 lembar & $\mathrm{Rp}$ & 157,500 \\
\hline & 6 tali kor & $\mathrm{Rp}$ & 48,000 \\
\hline \multirow[t]{4}{*}{$12 / 3 / 2018$} & 7 tali kor & $\mathrm{Rp}$ & 56,000 \\
\hline & 2 cling & $\mathrm{Rp}$ & 7,150 \\
\hline & kalkulator & $\mathrm{Rp}$ & 133,500 \\
\hline & soklin lantai & $\mathrm{Rp}$ & 23,800 \\
\hline $16 / 03 / 2018$ & 9 kertas jasmin & $\mathrm{Rp}$ & 85,500 \\
\hline \multirow[t]{2}{*}{$19 / 03 / 2018$} & albuni & $\mathrm{Rp}$ & 8,000 \\
\hline & kartu halo & $\mathrm{Rp}$ & 292,430 \\
\hline $24 / 03 / 2018$ & aqua isi ulang & $\mathrm{Rp}$ & 7,000 \\
\hline \multirow[t]{2}{*}{$26 / 03 / 2018$} & 70 lembar kertas & $\mathrm{Rp}$ & 122,000 \\
\hline & 3 lem fox & $\mathrm{Rp}$ & 51,000 \\
\hline $28 / 03 / 2018$ & aqua isi ulang & $\mathrm{Rp}$ & 10,000 \\
\hline 29/03/2018 & 70 lembar kertas & $\mathrm{Rp}$ & 122,500 \\
\hline \multirow[t]{6}{*}{$30 / 03 / 2018$} & transportasi & $\mathrm{Rp}$ & 24,000 \\
\hline & angkat barang & $\mathrm{Rp}$ & 60,000 \\
\hline & parkir & $\mathrm{Rp}$ & 28,000 \\
\hline & bahan bakar & $\mathrm{Rp}$ & 40,000 \\
\hline & telpon & $\mathrm{Rp}$ & 292,430 \\
\hline & air & $\mathrm{Rp}$ & 143,214 \\
\hline \multirow[t]{5}{*}{$31 / 03 / 2018$} & gaji Nur & $\mathrm{Rp}$ & $2,500,000$ \\
\hline & gaji Wian & $\mathrm{Rp}$ & $1,900,000$ \\
\hline & gaji Ririn & $\mathrm{Rp}$ & $1,750,000$ \\
\hline & gaji Andro & $\mathrm{Rp}$ & $2,200,000$ \\
\hline & TOTAL & $\mathbf{R p}$ & $10,078,524$ \\
\hline
\end{tabular}

Tabel 4.2 Buku Kas Keluar Perusahaan Bahaga Manado. Dari jurnal-jurnal yang ada, dapat dilihat untuk pengeluaran kas di catat per tanggal terjadinya transaksi pengeluaran kas. Yang di maksud disini adalah jumlah dari hasil pengeluaran kas yang terjadi pada setiap tanggal perusahaan Bahaga Manado melakukan transaksi pengeluaran kas yang di catat ke dalam buku kas keluar yang di miliki perusahaan Bahaga Manado. 


\begin{tabular}{|llc|}
\hline \multicolumn{1}{c}{ Tabel 4.3 } & Rekapitulasi Bulan Maret 2018 Bahaga Manado \\
\hline \multicolumn{1}{|c|}{ Modal Awal } & Kas Masuk & Rp 15.525.000 \\
& Kas Keluar & $\underline{\text { Rp 13.125.000 }}$ \\
Jumlah & & $\underline{\text { Rp 3.046.476 }}$ \\
Modal Akhir & & $\underline{\text { Rp 18.571.476 }}$ \\
& & \\
\hline
\end{tabular}

Dari Tabel 4.3 di atas dapat di lihat bahwa perusahaan Bahaga Manado membuat Rekapitulasi jumlah Kas Masuk dan Kas Keluar selama bulan Maret kemudian jumlah kas masuk tersebut dikurangkan dengan jumlah kas keluar sehingga di peroleh hasil dan selanjutnya hasil tersebut di tambahkaan dengan modal awal yang di tanamkan perusahaan Bahaga Manado pada awal bulan maret sehingga di peroleh hasil modal akhir bulan maret tahun 2018 perusahaan Bahaga Manado.

\subsection{Pembahasan}

Berdasarkan hasil penelitian yang dilakukan pada perusahaan Bahaga Manado maka berikut hasil pembahasan yang berupa perbandingan laporan keuangan Bahaga Manado dengan Standar Akuntansi Keuangan Entitas Tanpa Akuntabilitas Publik yang disajikan pada Tabel 4.4

Tabel 4.4 Perbandingan Laporan Keuangan Bahaga Manado dengan SAK ETAP

\begin{tabular}{|l|c|}
\hline SAK ETAP atas Laporan Keuangan & Penerapannya pada Bahaga Manado \\
\hline 1. Neraca & $\begin{array}{c}\text { Tidak diterapkan laporan keuangan bentuk neraca } \\
\text { pada Laporan Keuangan Bahaga Manado }\end{array}$ \\
\hline 2. Laporan Laba Rugi & $\begin{array}{c}\text { Tidak diterapkan laporan Laba Rugi pada Laporan } \\
\text { Keuangan Bahaga Manado }\end{array}$ \\
\hline 3. Laporan Arus Kas & $\begin{array}{c}\text { Tidak diterapkan laporan Arus Kas pada Laporan } \\
\text { Keuangan Bahaga Manado }\end{array}$ \\
\hline 4. Laporan Perubahan Ekuitas & $\begin{array}{c}\text { Tidak diterapkan laporan Perubahan Ekuitas pada } \\
\text { Laporan Keuangan Bahaga Manado }\end{array}$ \\
\hline 5. Catatan Atas Laporan Keuangan & $\begin{array}{c}\text { Tidak diterapkan Catatan Atas Laporan Keuangan } \\
\text { pada Laporan Keuangan Bahaga Manado }\end{array}$ \\
\hline
\end{tabular}

Dari Tabel 4.4 diatas, yang merupakan hasil pembahasan maka dapat dilihat bahwa penyajian laporan keuangan perusahaan Bahaga Manado belum sepenuhnya menyusun laporan keuangan yang sesuai dengan Standar Akuntansi Keuangan Entitas Tanpa Akuntabilitas Publik. Oleh karena perusahaan Bahaga Manado belum membuat laporan keuangan yang sesuai denga Standar Akuntansi Keuangan Entitas Tanpa Akuntabilitas Publik (SAK ETAP), maka dari data-data yang ada penulis akan membuat laporan keuangan perusahaan Bahaga Manado yang sesuai dengan SAK ETAP. Berikut ini penyajian laporan keuangan perusahaan Bahaga Manado selama bulan Maret 2018. Pada Tabel 4.5 dapat dilihat laporan keuangan rugi/laba perusahaan Bahaga Manado periode bulan maret sebagai berikut. 
Tabel 4.5 Laporan Laba Rugi Bahaga Manado Bulan Maret 2018 BAHAGA MANADO

Laporan Laba Rugi

Periode 01-31 Maret 2018

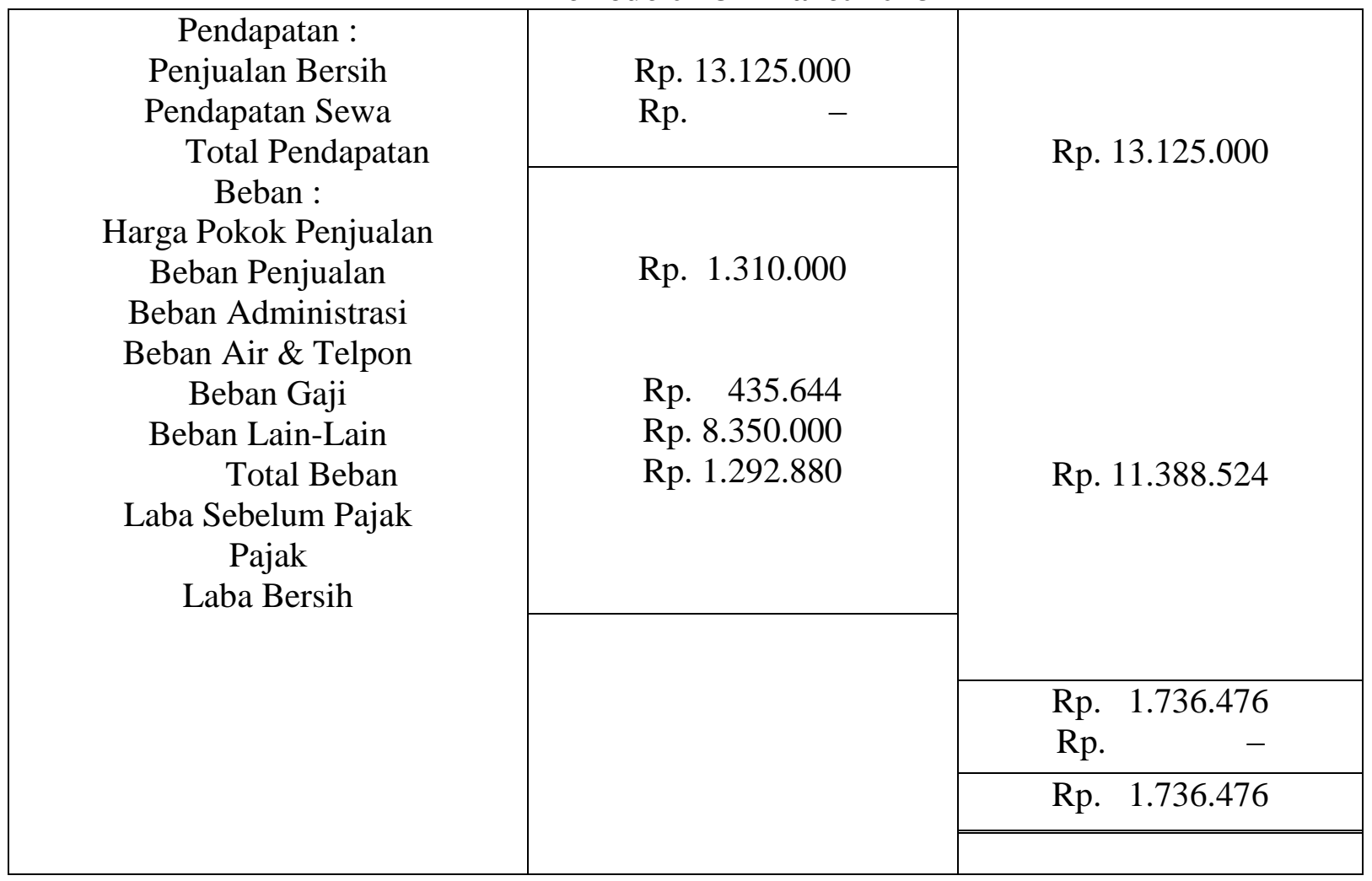

Tabel 4.5 di atas menunjukkan laporan rugi laba perusahaan Bahaga Manado selama bulan maret 2018 dengan penjualan bersih sebesar Rp. 13.125.000, harga pokok penjualan sebesar Rp. 1.210.000, beban air \& telpon sebesar Rp. 435.644, beban gaji yang terdiri dari 4 orang karyawan sebesar Rp. 8.350.000, dan beban lain-lain sebesar Rp. 1.292.880, sehingga total beban sebesar Rp. 11.388.524. Pengurangan dari penjualan bersih dengan total beban maka diperoleh lah laba bersih sebesar Rp. 1.736.476 .

Tabel 4.6 Laporan Perubahan Modal Bahaga Manado Bulan Maret 2018 BAHAGA MANADO

Laporan Laba Rugi

Periode 01-31 Maret 2018

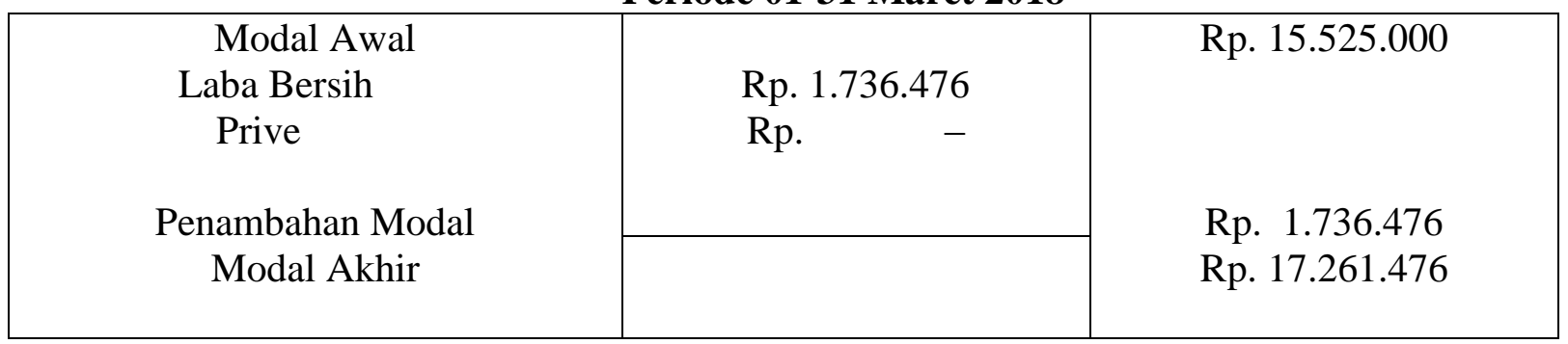

Tabel 4.6 di atas menunjukkan laporan perubahan modal perusahaan Bahaga Manado periode maret 2018 dengan modal awal sebesar Rp. 15.525.000, dan laba bersih dari hasil penjumlahan pada laporan laba rugi sebesar Rp. 1.736.476, hasil penjumlahan dari modal awal dengan laba bersih maka diperolehlh hasil modal akhri sebesar Rp. 17.261.476. 


\section{Tabel 4.7 Laporan Arus Kas Bahaga Manado Bulan Maret 2018 \\ BAHAGA MANADO \\ Laporan Laba Rugi \\ Periode 01-31 Maret 2018}

\begin{tabular}{|c|c|c|}
\hline \multirow{2}{*}{$\begin{array}{c}\text { Arus Kas Masuk: } \\
\text { Pelunasan Piutang Dagang } \\
\text { Laba Bersih Bulan Maret } \\
\text { Arus Kas Keluar: } \\
\text { Pengurangan Persediaan }\end{array}$} & $\begin{array}{lc}\text { Rp. } & - \\
\text { Rp. } 1.736 .476 \\
\end{array}$ & Rp. 1.736 .476 \\
\hline & Rp. 2.400 .000 & \multirow{2}{*}{ Rp. 2.400 .000} \\
\hline \multirow{4}{*}{$\begin{array}{c}\text { Pengurangan Kas } \\
\text { Kas Awal } \\
\text { Kas Akhir }\end{array}$} & & \\
\hline & & $\begin{array}{l}\text { Rp. }(663.524) \\
\text { Rp.15.525.000 }\end{array}$ \\
\hline & & Rp.14.861.476 \\
\hline & & \\
\hline
\end{tabular}

Pada Tabel 4.7 diatas yang merupakan laporan arus kas perusahaan Bahaga Manado periode bulan maret 2018 dengan arus kas masuk di peroleh dari laba bersih bulan maret sebesar Rp. 1.736.476, dan arus kas keluar di peroleh dari pengurangan persediaan sebesar Rp. 2.400.000. hasil pengurangan arus kas masuk dengan arus kas keluar maka di peroleh pengurangan kas sebesar Rp. 663.524 dan hasil penjumlahan dari pengurangan kas dengan kas awal sebesar Rp. 15.525.000 maka di peroleh kas akhir sebesar Rp. 14.861.476.

Tabel 4.8 Laporan Neraca Bahaga Manado Bulan Maret 2018

BAHAGA MANADO

Laporan Laba Rugi

Periode 01-31 Maret 2018

\begin{tabular}{|c|c|c|c|}
\hline \multicolumn{2}{|c|}{ Aktiva } & \multicolumn{2}{|c|}{ Pasiva } \\
\hline Aktiva Lancar : & & Utang Lancar : & \\
\hline Kas & Rp. 14.861.476 & Utang Dagang & \\
\hline Piutang Dagang & & Utang Listrik & \\
\hline Persediaan Barang & Rp. 2.400 .000 & Utang Pajak & \\
\hline Perlengkapan took & & Jumlah Utang & \\
\hline Perlengkapan Kantor & & Lancar & \\
\hline Iklan Dibayar Dimuka & & Modal & \\
\hline Sewa Dibayar Dimuka & & Modal Tn. Chris & Rp. 17.261.476 \\
\hline Jumlah & Rp. 17.261.476 & & \\
\hline Aktiva Tetap : & & & \\
\hline Peralatan Toko & & & \\
\hline Akm. Peny. Per. Toko & & & \\
\hline Peralatan Kantor & & & \\
\hline $\begin{array}{l}\text { Akm. Peny. Per. Kantor } \\
\text { Jumlah Aktiva }\end{array}$ & Rp. 17.261.476 & Jumlah Pasiva & Rp. 17.261.476 \\
\hline
\end{tabular}

Tabel 4.8 menunjukkan laportan neraca perusahaan Bahaga Manado periode bulan maret 2018 dengan kas sebesar Rp. 14.861.476, dan persediaan barang dagangan sebesar Rp. 
2.400.000 sehingga diperoleh jumlah aktiva sebesar Rp. 17.261.476. Untuk pasiva modal Tuan Chrisye sebesar Rp. 17.261.476 sehingga total jumlah pasiva sebesar Rp. 17.261.476. Dari laporan neraca perusahaan Bahaga Manado di atas memperlihatkan jumlah aktiva dan pasiva adalah sama.

\section{KESIMPULAN DAN SARAN \\ 5.1 Kesimpulan}

Berdasarkan hasil pengumpulan dan analisis data yang telah di laksanakan, maka dapat ditarik kesimpulan bahwa perusahaan Bahaga Manado menerapkan akuntansi sederhana pada sistem pencatatan dan pelaporan keuangan mereka dan belum menerapkan Standar Akuntansi Keuangan Entitas Tanpa Akuntabilitas Publik (SAK ETAP) dalam pencatatan laporan keuangannya di mana SAK ETAP menyaratkan Laporan Keuangan lengkap yang terdiri atas Neraca, Laporan Laba Rugi, Laporan Perubahan Ekuitas, Laporan Arus Kas dan Catatan Atas Laporan Keuangan (CALK). Hal ini disebabkan karena, tenaga kerja bagian keuangan perusahaan Bahaga Manado tidak memiliki pengetahuan yang memadai mengenai Standar Akuntansi Keuangan Entitas Tanpa Akuntabilitas Publik (SAK ETAP) sehingga menjadi faktor penyebab perusahaan Bahaga Manado belum sepenuhnya menerapkan SAK ETAP dan terbukti pada Laporan Keuangan perusahaan Bahaga Manado yang masih hanya mencatat jumlah Kas Masuk dan Kas Keluar saja.

\subsection{Saran}

Berdasarkan hasil penelitian yang di lakukan, maka beberapa hal yang dapat disarankan adalah sebagai berikut :

1. Secara umum pencatatan transaksi ke dalam beberapa buku jurnal yang telah di lakukan sudah cukup baik, namun perusahaan Bahaga Manado hendaknya melanjutkan pencatatan tersebut sampai pada laporan keuangan agar dapat diketahui secara jelas pendapatan, pengeluaran, dan keuantungan bersih yang diperoleh perusahaan.

2. Bagi perusahaan Bahaga Manado sebaiknya membuat atau menyusun Laporan Keuangan sesuai dengan standar akuntansi keuangan yang berlaku yaitu Standar Akuntansi Keuangan Entitas Tanpa Akuntabilitas Publik (SAK ETAP) sehingga laporan keuangan yang di hasilkan dapat mudah di mengerti dan dengan jelas memperlihatkan kinerja perusahaan.

3. Karena ketidaktahuan perusahaaan Bahaga Manado terhadap Standar Akuntansi Keuangan Entitas Tanpa Akuntabilitas Publik (SAK ETAP) disebabkan oleh kurangnya tenaga keuangan, maka perlu untuk mempekerjakan tenaga keuangan pada perusahaan Bahaga Manado. Hal ini di lakukan agar proses akuntansi dapat di lakukan oleh tenaga kerja yang berkopenten di bidangnya, sehingga dapat membantu perusahaan Bahaga Manado memperoleh hasil laporan kinerja perusahaan terutama kinerja keuangan sesuai dengan SAK ETAP.

\section{DAFTAR PUSTAKA}

Andriani, Lilya. Anantawikrama Tungga Atmadja dan Ni Kadek Sinarwati. 2014. Analisis Penerapan Pencatata Keuangan Berbasis SAK ETAP Pada Usaha Mikro Kecil Menengah (UMKM). Jurnal Akuntansi 2(1): 1-12.

Ardiyos. 2008. Kamus Besar Akuntansi. Citra Harta Prima, Jakarta.

Hery. 2012. Akuntansi Keuangan Menengah 1. Bumi Askara. Jakarta.

Ikatan Akuntansi Indonesia (AIA). 2009. Standar Akuntansi Keuangan Entitas Tanpa Akuntabilitas Publik. DSAK. Jakarta. 
Kieso, Donald., Jerry Weygandt., Terry Warfield. 2011. Intermediate Accounting, IFRS Edition. John Wiley \& Sons. Inc., USA.

Purba, Marisi. 2010. International Financial Reporting Standards, Konvergensi \& Kendala Aplikasinya di Indonesia. Graha Ilmu, Yogyakarta.

Soemarso. 2014. Akuntansi: Suatu Pengantar. Edisi Kelima. Cetakan Pertama. Salemba Empat. Jakarta.

Surya dan Adri Satriawan. 2012. Akuntansi Keuangan Versi IFRS. Graha Ilmu.Yogyakarta. Sugiono. 2015. Metode Peneliatian dan Pengembangan. Penerbit Alfabeta. Bandung. Undang-Undang Republik Indonesia Nomor 20 Tahun 2008. Usaha Mikro, Kecil, dan Menengah. 04 Juli 2008. Lembaran Negara Republik Indonesia Tahun 2008 Nomor 93. Jakarta.

Warren, C. S., Reeve, J. M., dan buchac, J. 2017. Financial Accounting Cengage Learning. Kanada.

Weygandt, Jerry J, Paul D. Kimel dan Donal E. Kieso. 2010. Financial Accounting IFRS Edition, John Weley and Sons Inc, Mew Jersey. 